\title{
MICROSTRUCTURE AND PROPERTIES OF SELECTED MAGNESIUM-ALUMINUM ALLOYS PREPARED FOR SPD PROCESSING TECHNOLOGY
}

\begin{abstract}
A growing interest in wrought magnesium alloys has been noticed recently, mainly due to development of various SPD (severe plastic deformation) methods that enable significant refinement of the microstructure and - as a result - improvement of various functional properties of products. However, forming as-cast magnesium alloys with the increased aluminum content at room temperature is almost impossible. Therefore, application of heat treatment before forming or forming at elevated temperature is recommended for these alloys. The paper presents the influence of selected heat treatment conditions on the microstructure and the mechanical properties of the as-cast AZ91 alloy. Deformation behaviour of the as-cast AZ61 alloy at elevated temperatures was analysed as well. The microstructure analysis was performed by means of both light microscopy and SEM. The latter one was used also for fracture analysis. Moreover, the effect of chemical composition modification by lithium addition on the microstructure of the AZ31-based alloy is presented. The test results can be helpful in preparation of the magnesium-aluminum alloys for further processing by means of SPD methods.
\end{abstract}

Keywords: magnesium alloys, severe plastic deformation, SPD, ECAP, tensile test, microstructure, fracture

\section{Introduction}

Application areas of magnesium alloys extend continuously. Due to their low density and high strength-to-weight ratio, magnesium alloys are used to manufacture a wide variety of products, eg. chassis and casings for cameras, laptops and mobile phones, car inner door panels, seat frames, steering wheels, engine blocks, many aerospace structural components, to name a few [1-3]. Low inertia, which results from its low density, is advantageous in rapidly moving parts, eg. car wheels. Selection of appropriate magnesium alloys for specific applications is preceded by analysis of many factors, including the mechanical properties, design, cost, environment, urbanization, recycling, availability etc. $[4,5]$. Thus, it is required to investigate various aspects regarding individual alloys, optimize their chemical composition, study issues of their metallurgical preparation and further processing: castability, formability, heat treatment conditions, surface treatment, corrosion resistance, fatigue behaviour etc. [6-13].

Two categories of magnesium alloys are usually used in practical applications. The first one includes magnesium alloys with $2-10 \% \mathrm{Al}$ content and the minor content of $\mathrm{Zn}$ and $\mathrm{Mn}$. These alloys are produced with relatively low costs and their mechanical quality rapidly falls down at higher temperatures. The second category involves magnesium alloys with a wide variety of chemical elements (eg. $\mathrm{Zn}, \mathrm{Th}, \mathrm{Ag}$ and $\mathrm{Si}$ ) instead of $\mathrm{Al}$, but always with the content of $\mathrm{Zr}$ which assures the finegrained structure and higher mechanical quality. These alloys have better properties at higher temperatures but more expensive elements together with the special production technology cause higher production costs.

Magnesium alloys are subjected to heat treatment mostly for the purpose of improving their mechanical properties or as an intermediate operation, to prepare the alloy to subsequent operations. The type of heat treatment depends mainly on the chemical composition of an alloy.

Significant improvement of the magnesium alloys properties can be obtained also by application of severe plastic deformation (SPD) methods, eg. ECAP, KoBo extrusion [14-17]. However, application of SPD methods to process magnesium alloys with the increased aluminum content in the as-cast state is impossible, therefore heat treatment before processing of those is recommended.

The paper presents the effect of selected heat treatment conditions on the microstructure and properties of the AZ91 alloy. The scope of work comprised determination of the mechanical properties by means of the tensile test and investigations of the microstructure by means of the optical microscopy and the scanning electron microscopy. Two other aspects of improving magnesium alloys formability has been analysed as well: form-

\footnotetext{
* VŠB - TECHNICAL UNIVERSITY OF OSTRAVA, CZECH REPUBLIC

** RZESZÓW UNIVERSITY OF TECHNOLOGY, POLAND

*** SILESIAN UNIVERSITY OF TECHNOLOGY, POLAND

\# Corresponding author: stanislav.rusz@vsb.cz
} 
ing at elevated temperatures (on the basis of tensile tests results obtained for the AZ61 alloy in the as-cast state) and the effect of chemical composition modification (by means of lithium addition to the remelted magnesium-aluminum alloy).

\section{Investigated materials and test conditions}

The EDX spectrometer was used to determine the amount of main alloying elements in the investigated alloys. Their chemical compositions are given in Table 1.

TABLE 1

Chemical composition of the investigated alloys in wt \%

\begin{tabular}{|c|c|c|c|c|c|}
\hline \hline Alloy & Al & Zn & Mn & Si & Li \\
\hline AZ61 & 5.92 & 0.49 & 0.15 & 0.037 & - \\
\hline AZ91 & 8.15 & 0.76 & 0.21 & 0.041 & - \\
\hline Mg-Li4 & 2.65 & 0.52 & 0.24 & 0.031 & 4.0 \\
\hline Mg-Li7 & 2.54 & 0.41 & 0.18 & 0.039 & 7.5 \\
\hline
\end{tabular}

In order to check the effect of heat-treatment conditions on the microstructure and properties of the AZ91 alloy, $10 \times 20 \times 150 \mathrm{~mm}$ cast samples were subjected to solutioning (the T4 temper). Samples were pre-heated at $375^{\circ} \mathrm{C}$ by 3 hours and then heated at $415^{\circ} \mathrm{C}$ by 18 hours. After that, three cooling variants were applied: in the air (HT1), the water (HT2) and a furnace (HT3) [6].

Testing of AZ91 and AZ61 mechanical properties at room temperature was performed on the INOVA - TSM 50 tensile testing machine. The crosshead rate $6 \mathrm{~mm} / \mathrm{min}$ was used. $90 \mathrm{~mm}$ long and $6 \mathrm{~mm}$ dia. tensile samples (with $30 \mathrm{~mm}$ long and $4 \mathrm{~mm}$ dia. gauge parts) were taken from the aforementioned cast samples.

In order to check the effect of deformation temperature on the formability of AZ61 alloy, several tensile tests at temperature range of $20-250^{\circ} \mathrm{C}$ were conducted on the INOVA - TSM 20 tensile testing machine. $115 \mathrm{~mm}$ long and $6 \mathrm{~mm}$ dia. samples were used this time. However, the same gauge parts of the tensile samples and the same crosshead rate were used as during the tests at room temperature.

The NEOPHOT 2 optical microscope as well as the JEOL $50 \mathrm{~A}$ scanning electron microscope were used for microstructure investigations.

Samples for microstructure investigations of ultra-light magnesium-aluminum alloys with lithium addition (based on the remelted AZ31 alloy) were taken from $50 \mathrm{~mm}$ long and $40 \mathrm{~mm}$ dia. ingots [18].

\section{Test results and discussion}

Microstructures of the investigated AZ91 and AZ61 alloys in the as-cast condition are shown in (Fig. 1). The AZ91 alloy microstructure (Fig. 1a) consists of the solid solution of aluminium in magnesium (an $\alpha$-phase), surrounded by formations of $\mathrm{Mg}_{17} \mathrm{Al}_{12}$ intermetallic (a $\beta$-phase), nearly continuously distributed in the interdendritic areas along grain boundaries. Moreover, in the vicinity of the $\beta$ phase precipitations the presence of an $\alpha+\beta$ eutectic was revealed. The eutectic obtained takes the form of the so-called divorced eutectic, where the initiating particles dissolved in the solid solution precipitate during the casting process at the boundaries of the initiating solid solution. In the AZ61 alloy, smaller amount of the $\mathrm{Mg}_{17} \mathrm{Al}_{12}$ phase is observed (Fig. 1b).
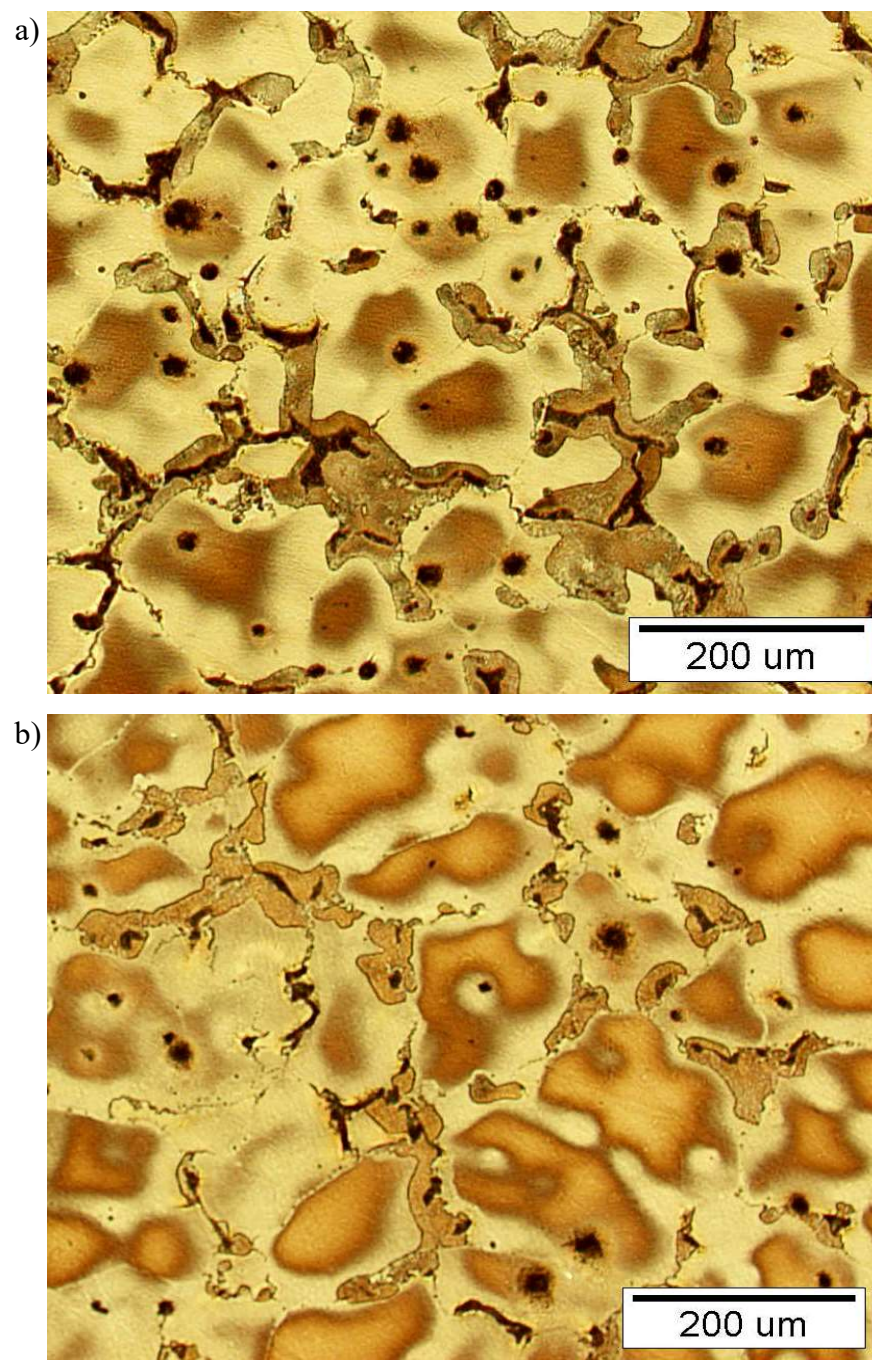

Fig. 1. Microstructure of the investigated magnesium alloys in the ascast state: a) AZ91, b) AZ61

Microstructures of the AZ91 alloy after conducted heat treatment are shown in (Fig. 2). The amount of $\mathrm{Mg}_{17} \mathrm{Al}_{12}$ phase has been significantly reduced after cooling in air and water - due to its dissolving (see Fig. 2a,b, respectively), while in the case of cooling in a furnace this phase appears again under eutectic temperature in a form of the fine lamellar precipitates in nearly all grains (Fig. 2c) [9].

The conducted heat treatment operations caused a remarkable effect on the AZ91 mechanical properties. It is especially distinct when compared with rather small differences in relevant properties obtained for the as-cast AZ61 and AZ91 alloys. Results of the tensile tests are collected in Figure 3. As it is seen, 
the yield strength rises just 7\% with the increasing content of aluminum in an alloy while the ultimate tensile strength and the percentage elongation slightly decrease. The performed solution heat treatment caused significant modification of the AZ91 alloy mechanical properties. A considerable increase of the percentage elongation (it's 3 times higher) and the ultimate tensile strength (it's 58\% higher) has occurred after heat treatment with cooling in air. The similar (even slightly higher) effect has been obtained for cooling in water. The high value of yield strength after solution heat treatment with cooling in furnace is an effect of intensive refining of the $\mathrm{Mg}_{17} \mathrm{Al}_{12}$ phase.

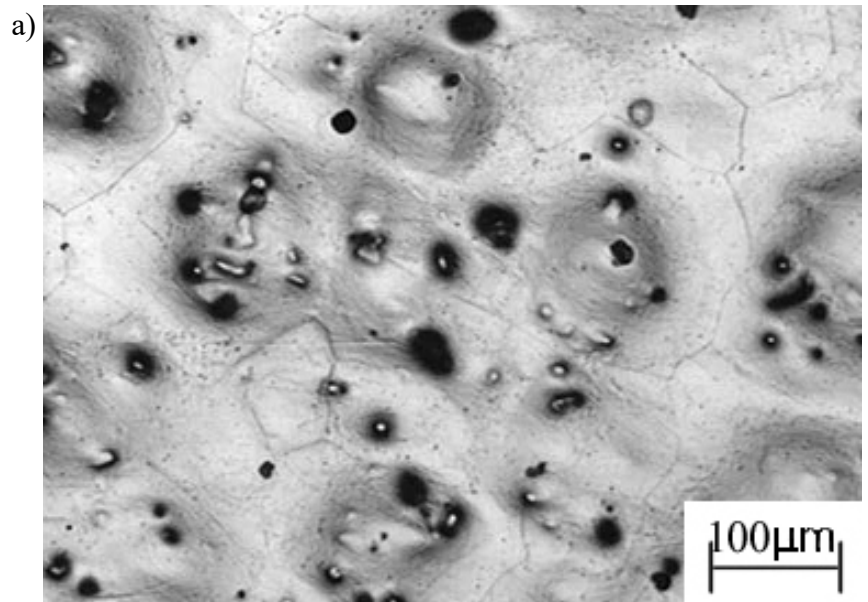

b)

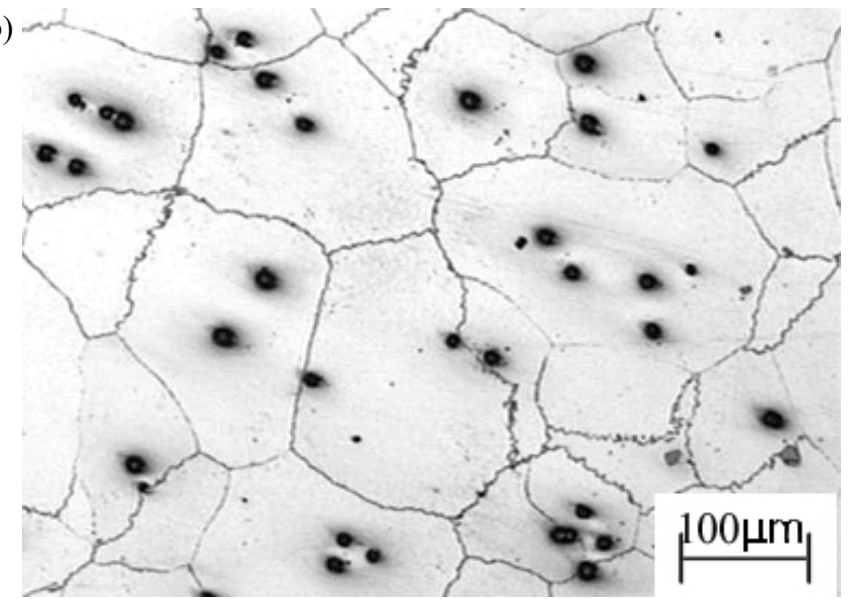

c)

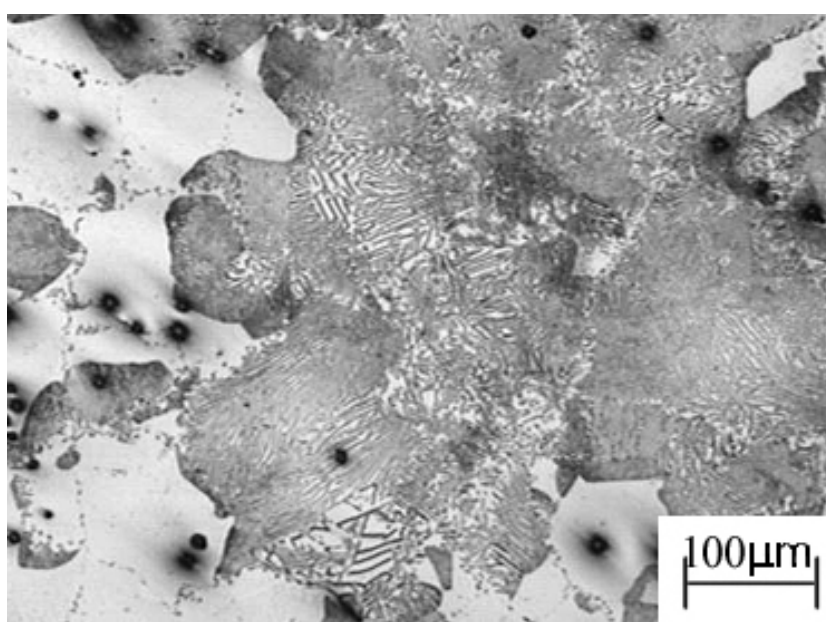

Fig. 2. Microstructure of AZ91alloy: a) after T4 and cooling in air, b) after T4 and cooling in water c) after T4 and cooling in a furnace
Results of the AZ61 alloy tensile tests conducted at elevated temperatures are collected in Fig. 4. As it was expected, the stress swiftly decrease with increasing temperature of the test while the elongation rises. The higest ductility exhibited the sample sunjected to tensile test at $150^{\circ} \mathrm{C}$. More than three times greater elongation than at room temperature was achieved in this case.

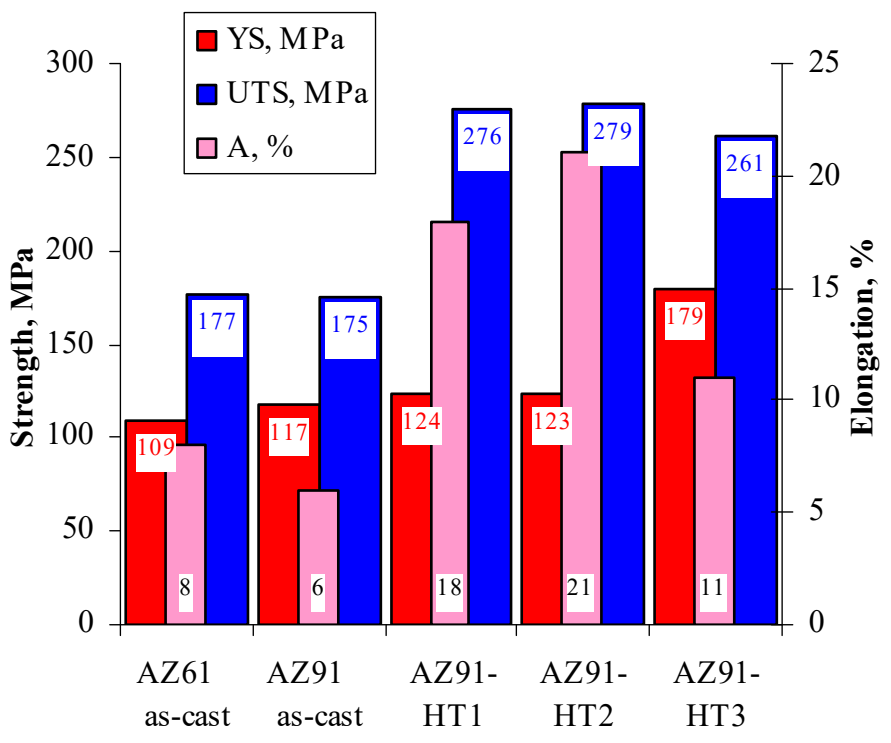

Fig. 3. Comparison of the proof strength, the ultimate strength and percentage elongation obtained for various samples subjected to tensile tests at room temperature

However, the sample tested at $240^{\circ} \mathrm{C}$ did not follow the rule and its elongation was just slithly higher than the sample at room temperature. The explanation of this issue was found in the microstructure. In the samples tested at $240^{\circ} \mathrm{C}$ and $361^{\circ} \mathrm{C}$ partial dissolution and coagulation of the massive phase occurred (Fig. 5). These processes are accompanied by forming of the micro-pores in the interdendritic areas, contributing also to initiation of crack propagation along the phase boundary. Good ductility of the sample tested at $360^{\circ} \mathrm{C}$ is probably due to occurrence of quasi-liquid state in the interdendritic areas.

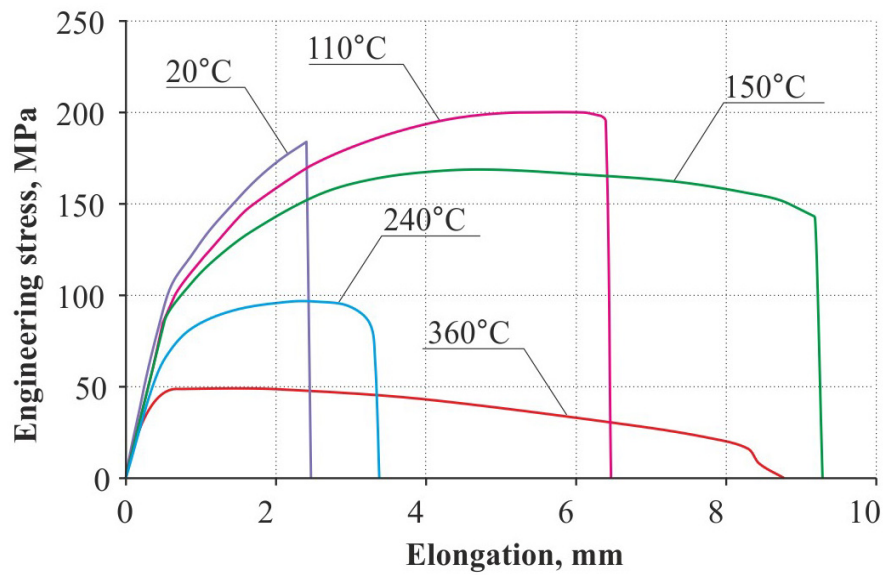

Fig. 4. Engineering stress vs. elongation curves obtained for AZ61 samples subjected to tensile tests at elevated temperatures 
a)

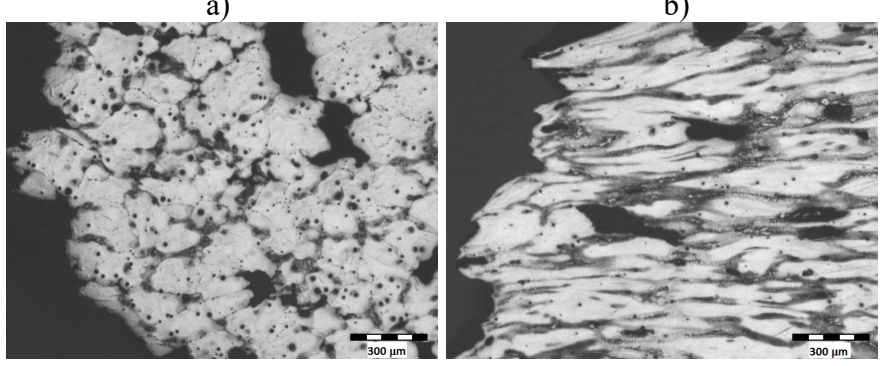

Fig. 5. The microstructure of the AZ61 samples on the longitudinal sections in the fracture area, after tests at: a) $240^{\circ} \mathrm{C}$, b) $360^{\circ} \mathrm{C}$

Selected details of AZ91 alloy microstructure in the initial as-cast state and after solution heat treatment with cooling in water as well as the maps of selected elements distribution determined by SEM analysis are shown in (Figs. 6,7) respectively. After detailed analysis the precipitated phases as $\mathrm{Mg}_{2} \mathrm{Si}$ and $\mathrm{MnAl}_{4}$ were found.

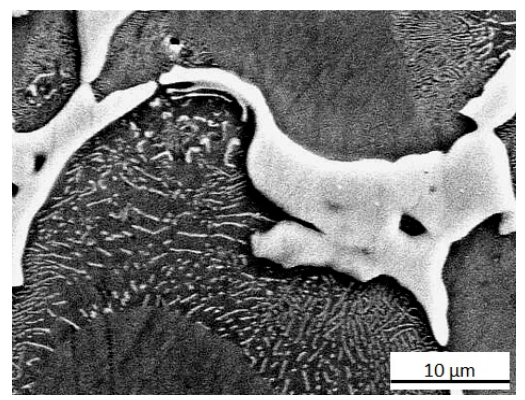

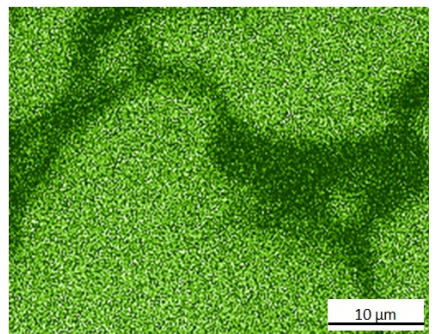

$\mathrm{Mg}$

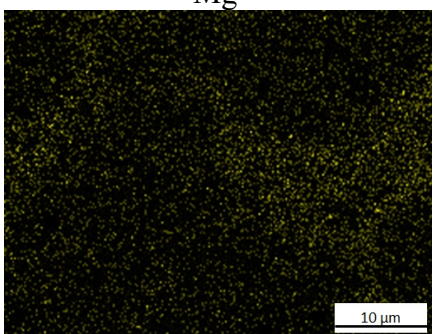

$\mathrm{Zn}$

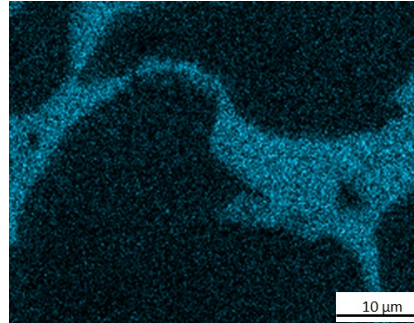

$\mathrm{Al}$

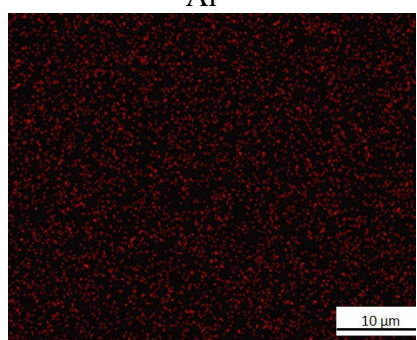

$\mathrm{Mn}$
Fig. 6. Selected SEM image of AZ91 alloy in initial as-cast state and the maps of selected elements distribution

The metallographic investigations enabled to analyse also the fracture behaviour of tested samples. A fracture surface of the AZ91 alloy sample in the initial as-cast state is presented in (Fig. 8a). A brittle interdendritic character of fracture is observed. The micro-pores occur in the interdendritic areas and initiate cracking along the phase boundary. A character of the fracture area in the as-cast AZ61 alloy sample is liitle more ductile (Fig. 8b).

The effect of heat treatment conditions on the fracture behaviour of the AZ91 alloy is presented in (Fig. 9). The fracture surface of the sample cooled in water after solutioning contains more plastic areas (Fig. 9a) while (Fig. 9b) shows that in the sample cooled in a furnace the fracture occurred on fine lamellas of the $\mathrm{Mg}_{17} \mathrm{Al}_{12}$ precipitates.

The effect of deformation temperature on the fracture behaviour of the AZ61 alloy is presented in (Fig. 10). It was found that the inter-crystalline splitting along the boundaries of original dendrites dominates in the fracture areas nearly within the whole tested temperature range. Only in the sample tested at $360^{\circ} \mathrm{C}$ ductile hollow fracture prevails (Fig. 10b).

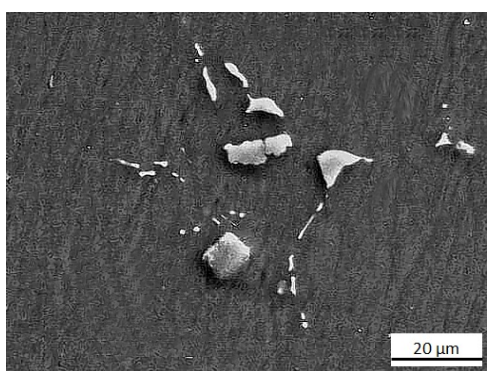

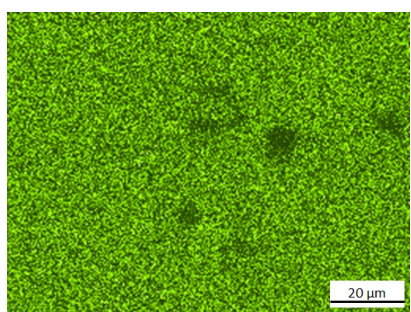

$\mathrm{Mg}$

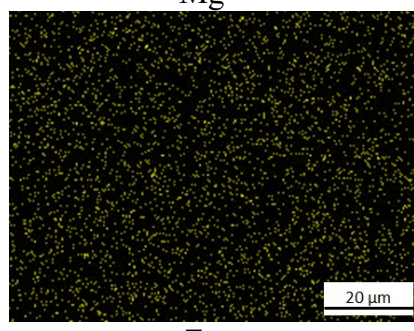

$\mathrm{Zn}$

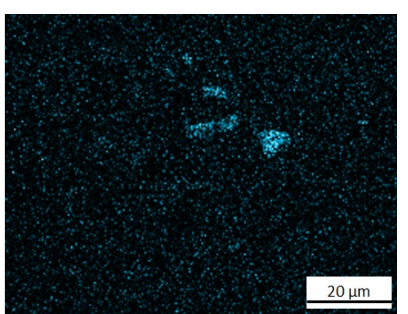

$\mathrm{Al}$

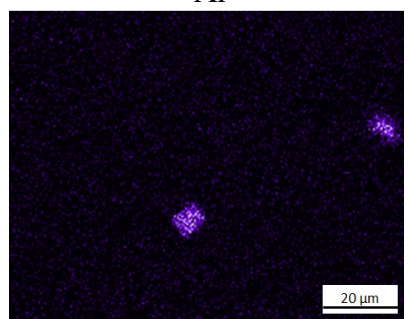

$\mathrm{Si}$
Fig. 7. Selected SEM image of AZ91 alloy after solution heat treatment with cooling in water and the maps of selected elements distribution

Microstructures of the investigated magnesium alloys with lithium addition are shown in (Fig. 11). The alloy with $4 \%$ content of lithium exhibits a single-phase microstructure of solid solution of lithium in magnesium with the hexagonal close packed lattice structure ( $\alpha$ phase) while the alloy containing 7.5\% of Li has a two-phase microstructure consisting the abovementioned $\alpha$ phase and a $\beta$ phase - the solid solution magnesium in lithium with the body centered cubic lattice structure. Existence of the $\beta$ phase makes the alloy more ductile [19-21]. The eutectic area with complex intermetallic phases is present as well. For detailed phases description the SEM analysis will be performed soon. 


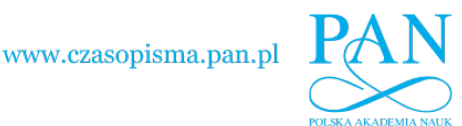

a)

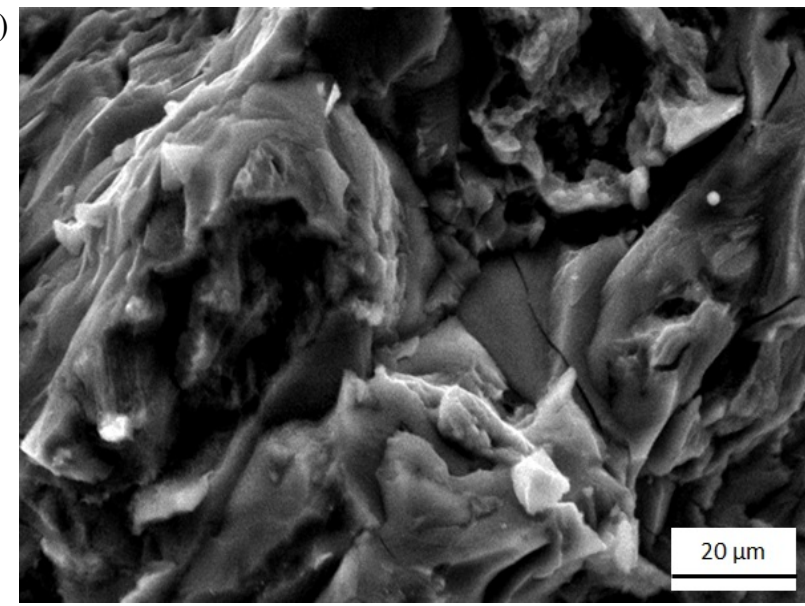

b)

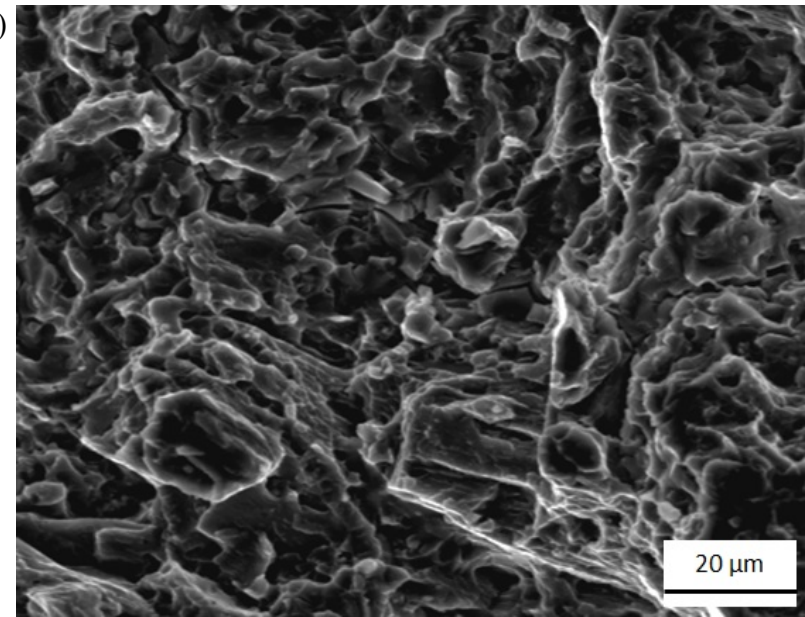

Fig. 8. SEM images of the fracture area in a) AZ91 alloy b) AZ61 alloy in the as-cast state

\section{Conclusions}

Magnesium-aluminum alloys belong to the group of materials that are rather hard to form. Different methods for improving of their ductility are widely welcomed. The aforementioned results prove that extensive knowledge on how the chemical composition and conditions of various technological processes affect the microstructure and properties of a workpiece is crucial for proper selection and preparation of an $\mathrm{Mg}-\mathrm{Al}$ alloy for further processing by any of SPD method. The following specific conclusions can be drawn:

- $\quad$ the microstructure of the AZ61 and AZ91 alloys in the ascast state consists of the solid solution and $\mathrm{Mg}_{17}(\mathrm{Al}, \mathrm{Zn})_{12}$ minority phase in both massive and dispersed form; thanks to detailed SEM analysis, the precipitated phases as $\mathrm{Mg}_{2} \mathrm{Si}$ and $\mathrm{MnAl}_{4}$ were revealed as well;

- the microstructure of these alloys has interdendritic character, minority phases are fairly continuously distributed in the interdendritic areas, which represent regions suitable for initiation and propagation of cracks under load and the brittle character of fractures dominates;

- the results of tensile tests conducted at ambient temperature show that yield strength rises with increasing content of a)

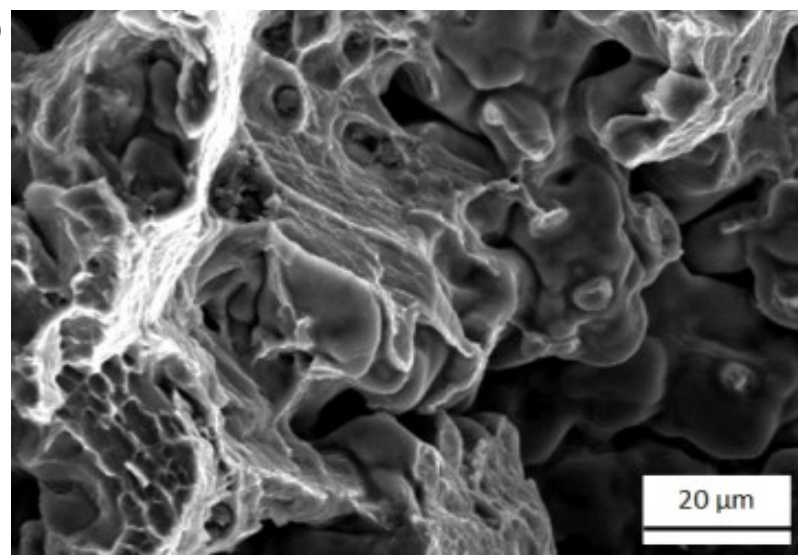

b)

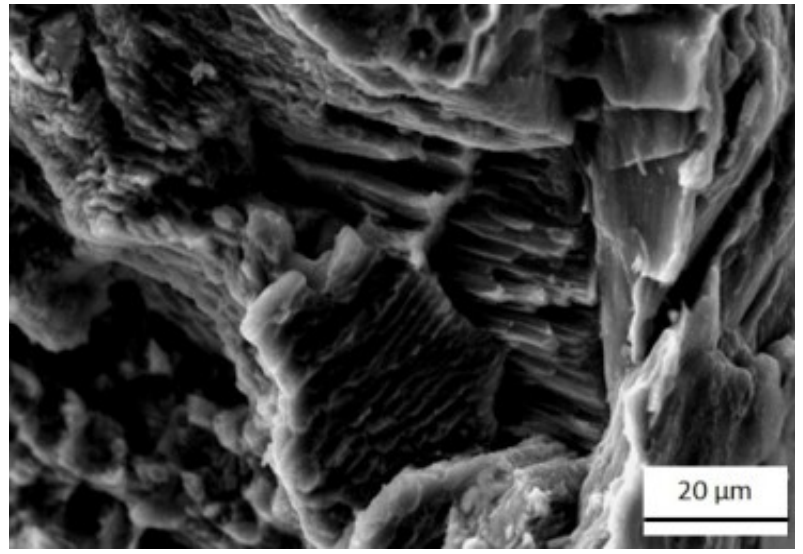

Fig. 9. SEM images of the fracture area in AZ91 alloy after solution heat treatment a) with cooling in water, b) with cooling in a furnace

a)

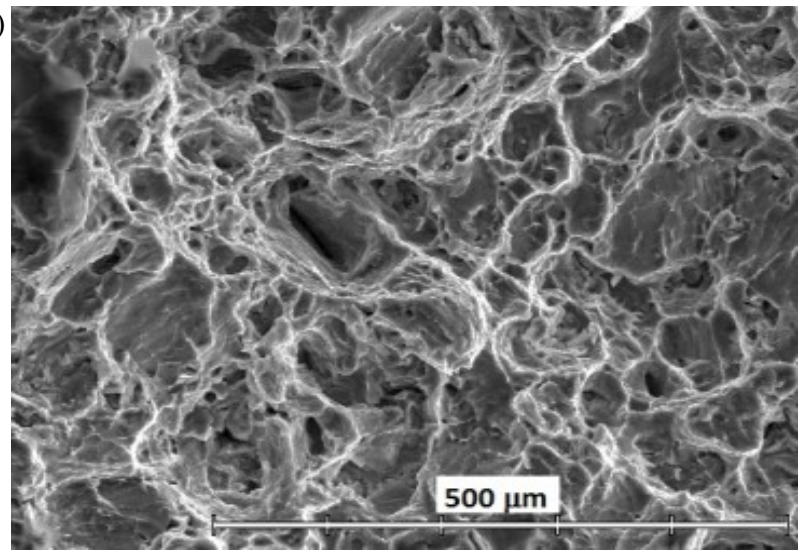

b)

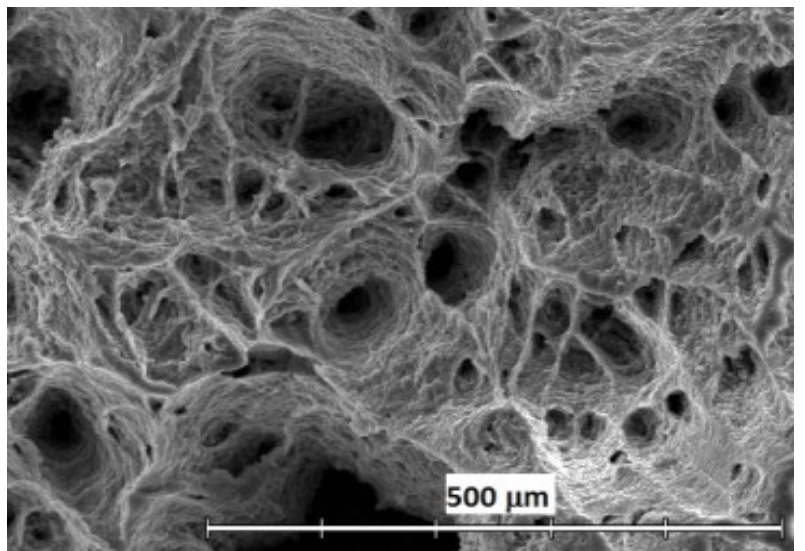

Fig. 10. SEM images of the fracture area in AZ61 alloy after tensile test at a) $150^{\circ} \mathrm{C}$, b) $360^{\circ} \mathrm{C}$ 
a)

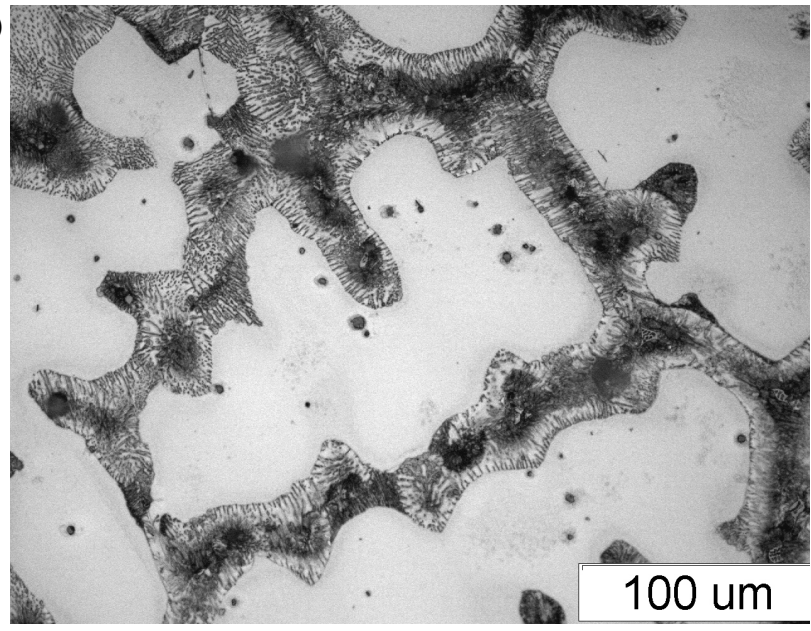

b)

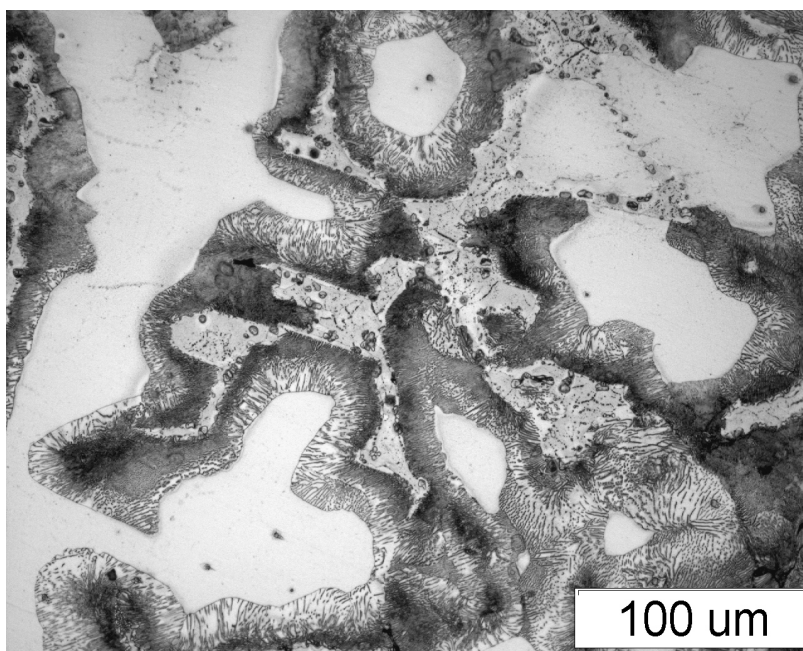

Fig. 11. Microstructure of the investigated magnesium - lithium alloys in the as-cast state: a) $4 \%$ of $\mathrm{Li}$, b) $7.5 \%$ of $\mathrm{Li}$

aluminum in magnesium alloys while both ultimate tensile strength and percentage elongation slightly decrease;

- the significant modification of AZ91 alloy mechanical properties can be obtained by solution heat treatment; the variant with cooling in water was the most beneficial for increasing the AZ91 alloy ductility;

- increasing deformation temperature to approx. $150^{\circ} \mathrm{C}$ causes significant rise of the AZ61 alloy ductility; during heating at higher temperatures partial dissolution of minority phases occurs, however homogenisation of microstructure is accompanied by simultaneous forming of inter-granular non-integrities, what negatively affects strength and plastic properties; increased ductility observed at $360^{\circ} \mathrm{C}$ can result from certain homogenisation of microstructure or quasiliquid state in interdendritic areas;

- as it comes from the comparison of the $\mathrm{Mg}-4 \% \mathrm{Li}$ and $\mathrm{Mg}-7.5 \% \mathrm{Li}$ microstructures, the latter (two-phase) alloy exhibits greater potential for processing by SPD methods due to existence of the $\beta$ phase with bcc lattice structure which represents much higher ductility than the hep lattice of the $\alpha$ phase.

\section{Acknowledgements}

Research conducted in the framework of the projects: „Support research and development in the Moravian-Silesian Region 2013 DT 1 - International research teams" $(02613 / 2013 / \mathrm{RRC})$ - financed from the budget of the Moravian-Silesian Region, Czech Republic, and "Modern material technologies in aerospace industry", (POIG.01.01.02-00-015/08-00) supported by Structural Funds in the Operational Programme - Innovative Economy (IE OP) financed from the European Regional Development Fund. Financial support is gratefully acknowledged.

This paper was also created with the financial support of Association of Graduates of the Faculty of Metallurgy and Materials Engineering of Silesian University of Technology, Poland.

\section{REFERENCES}

[1] M.K. Kulekci, Int. J. Adv. Manuf. Technol. 39, 851-865 (2008).

[2] A.A. Luo, Journal of Magnesium and Alloys 1, 2-22, (2013.)

[3] Magnesium Alloys and their Application, K.U. Kainer (Ed.), 2000 Wiley-VCH, Weinheim.

[4] H. Friedrich, S. Schumann, J. Mater. Proces. Tech. 117, 276-281 (2001).

[5] E. Aghion, B. Bronfin, Mater. Sci. Forum 350-351, 19-30 (2000).

[6] ASM specialty Handbook - Magnesium and Magnesium Alloys, M.M. Avedesian, H. Baker (Eds.), 3-84 (1999) ASM International.

[7] H. Baker, Physical properties of magnesium and magnesium alloys, The Dow Chemical Company, Midland (1997).

[8] Magnesium-Alloys and Technology, K.U. Kainer (ed.), 2003 Wiley-VCH, Weinheim, Germany.

[9] L.A. Dobrzański, T. Tański, L. Č́žžek, J. Madejski, Journal of AMME 32 (2), 203-210 (2009).

[10] D. Kuc, E. Hadasik, I. Schindler, P. Kawulok, R. Śliwa, Archives of Metallurgy and Materials 58 (1), 151-156 (2013).

[11] M. Cieśla, G. Junak, in: METAL 2015 Conf. Proceedings, Ostrava, Tanger, 631-635 (2015).

[12] M. Cieśla, Solid State Phenom. 211, 1662-9779 (2015).

[13] J. Przondziono, W. Walke, E. Hadasik, J. Szala, J.Wieczorek, Metalurgija 52 (2), 243-246 (2013).

[14] S. Rusz, L. Cizek, J. Kedron, S. Tylsar, M. Salajka, J. Dutkiewicz, M. Klos, E. Hadasik, Journal of Trends in the Development of Machinery and Associated Technology 16 (1), 51-54 (2012).

[15] S. Rusz, L. Cizek, S. Tylsar, J. Kedron, M. Salajka, E. Hadasik, T. Donic, Journal of Trends in the Development of Machinery and Associated Technology 16 (1), 55-58 (2012).

[16] T. Liu, W. Zhang, S.D. Wu, C.B. Jiang, S.X. Li, Y.B. Xu, Materials Science and Engineering A 360 (1), 345-349 (2003).

[17] S. Ziółkiewicz, M. Gąsiorkiewicz, Obróbka Plastyczna Metali 24 (2), 99-107 (2013).

[18] T. Mikuszewski, Metalurgija 53, 588-590 (2014).

[19] A. Białobrzeski, K. Saja, Archives of Foundry Engineering 11 (3), 17-20 (2011)

[20] T. Al-Samman, Acta Materialia 57, 2229-2242 (2009).

[21] D. Kuc, E. Hadasik, J. Mizera, T. Mikuszewski, Solid State Phenom. 212, 11-14 (2014). 